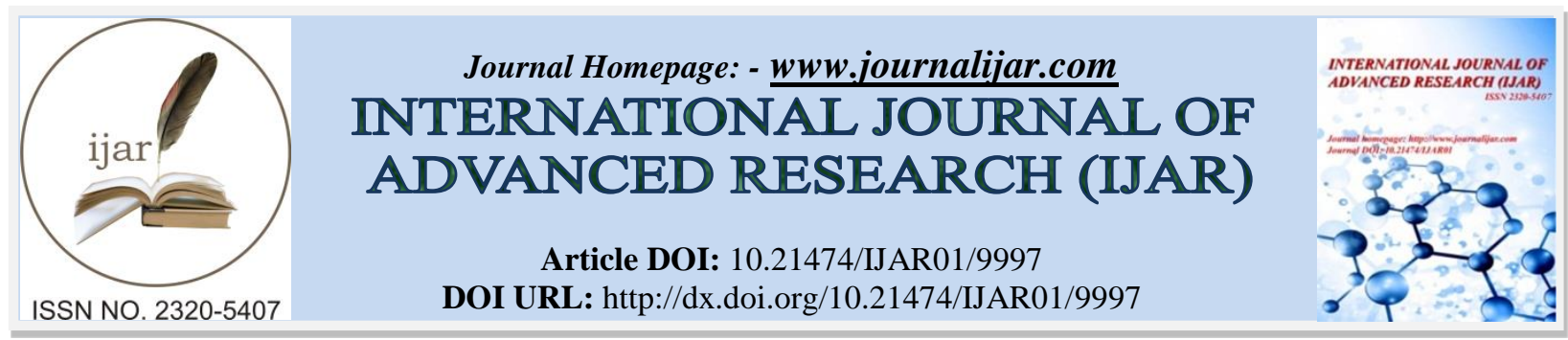

RESEARCH ARTICLE

\title{
A STUDY OF BASIC COSTS FOR TRACKING TOTAL COST OF OWNERSHIP OF INFORMATION AND COMMUNICATION TECHNOLOGY IN AN ACADEMIC INSTITUTION: THE CASE OF THE INSTITUTE OF ACCOUNTANCY ARUSHA.
}

\author{
Victor Ngessa. \\ Lecturer - Institute of Accountancy Arusha, Informatics department.
}

\section{Manuscript Info}

Manuscript History

Received: 05 September 2019

Final Accepted: 07 October 2019

Published: November 2019

Key words:-

Total Cost of Ownership, ICT

Infrastructure Costs, Academic

Institutions ICT costs.

\section{Abstract}

This paper discusses the total cost of ownership (TCO) of an Information and Communication Technology (ICT) infrastructure in an academic Institution. The aim of this study is to encourage use of TCO analysis. ICT TCO shows all onetime costs and recurring costs and its analysis lead to later lower costs in maintenance and support. Interviews and documentary sources were used to collect data. Most indirect costs were impossible to determine. ICT TCO can be lowered by training users to properly use ICT facilities and implement management best practices in the deployment, in the day-to-day Computer operations and in the retirement processes.

Copy Right, IJAR, 2019,. All rights reserved.

\section{Introduction:-}

An organization's ICT infrastructure encompasses all forms of computing systems, telecommunications and networks. These are tools for gathering, storing, retrieving, processing, analyzing and transmitting information in an organization Jeremy G., Charles K., \& Christine Z. (2004).

Because of advantages ICT offers, organizations (including academic institutions) in developing countries are working very hard to implement the technologies to catch up with the developed countries Bankole et al, (2013), ASEAN (2011), Kooshki, M. \& Ismail R. (2011), Bollou, F. (2010), Shirazi et al (2009), Thompson, Garbacz (2008), Jorgenson et al (2005), Kuppusamy et al. (2005). As a result of adoption and use of these technologies availability and quality of services have gone up and costs have gone down Worldbank (2011).

Putting aside advantages ICT offers to organizations, many organizations do not have accurate idea of total ICT infrastructure costs. For many organizations, the focus is on the purchase price and performance of their computers, networks and systems in general. This is evidenced by Giray, G. \& Tuzun, E. (2018) who point out that when selecting Enterprise Resource Planning (ERP) solutions many organizations neglect maintenance costs for ERP. While organizations neglect these costs their study found that customizations and add-on procurement have significant impact on the overall total cost of ERP systems.

Various surveys indicate that the initial purchase price represents only between $20 \%$ and $25 \%$ of the total cost associated with owning a Personal computer (PC) over its lifetime, Gartner (2008). Fortune and Economist magazines estimate these costs to be anywhere from $\$ 4,000$ - $\$ 10,000$ per device per year. 
This paper start by explaining what ICT TCO constitutes and goes further explaining what are some of the advantages and limitations of it. Later, how determination of ICT TCO can be made is explained followed by how it can be reduced. At the end there is presentation and discussion of findings and conclusion.

Primary data were collected at the Institute of Accountancy Arusha and data from the Internet were also used for discussion.

\section{Literature Review}

According to Wikipedia (2019), TCO is a financial estimate designed to help organizations assess direct and indirect costs related to the purchase and all other cost aspects in the further use and maintenance of the equipment, device, or system considered of any capital investment, such as (but not limited to) computer software or hardware.

For the case of ICT infrastructures, this includes the costs of purchase, implementation, training support personnel and the users of the system, costs associated with failure or outage (planned and unplanned), diminished performance incidents (i.e. if users are kept waiting), costs of security breaches (in loss of reputation and recovery costs), costs of disaster preparedness and recovery, floor space, electricity, development expenses, incremental growth, decommissioning, etc.

\section{Direct vs. Indirect Cost of Owning ICT}

Direct costs are costs that traditionally form the area that organizations find easiest to measure and as a result they often receive excessive focus. Basically, direct costs are made up of labor and capital costs. These are costs for hardware and software acquisition, installations, training, support, maintenance, and costs to acquire and maintain network infrastructure, Toshiba (2007), Toshiba-europe (2019), \& Investopedia (2019).

On the other hand, indirect costs are more elusive and difficult to measure and rationalize. They are hidden. The impacts of these costs are often underestimated or completely dismissed.

Survey conducted by Gartner (2003); however, show that indirect costs can represent as much as $60 \%$ - of the total cost of managing and owning an IT infrastructure. Indirect costs typically reflect the factors that drive and are driven by, direct cost decisions; for example downtime or quality of service. Most importantly, indirect costs are often a result of misdirected funding in direct costs like technical support, training and help desk; therefore, making those costs look artificially low, and further, shift these costs to business units reducing available resources to perform business tasks.

For example, it might seem like a good decision to reduce direct costs by spending less on hardware purchases or staff development. However, if the result of such action is to deliver services with inappropriate service level agreements, or less reliable hardware that fails more often, the ultimate outcome might be to shift the comparatively meager savings from the direct side into comparatively significant increased costs in the indirect side.

Other indirect costs include the futz factor which is the time users spend using equipment for personal needs, such as playing games and chatting with friends and retrofitting which refers to costs for upgrading electrical systems, cooling systems, and ventilation.

\section{Reasons for Considering ICT TCO}

TCO provide visibility to both one-time and recurring costs related to the implementation of an ICT investment. Focus on TCO lead to smaller costs in maintaining, supporting, and upgrading ICT infrastructures as organizations can use TCO methodology as a benchmarking tool to compare hardware and software vendors.

And because TCO includes all costs for the IT investment, businesses should be aware of TCO because obviously it is sensible to consider all costs before an asset is acquired. This means that Organizations using IT that have not addressed TCO experiences out-of-control cost increases.

\section{Challenges of TCO Analysis}

A number of studies point various limitations to TCO analysis. Measuring and getting accurate data to use in TCO analysis requires adequate training and experience. This makes TCO analysis expensive. Staff should also be trained on how to carry out adequate analysis and this takes time. For newer, larger and complicated systems the situation can even be more problematic and expensive. On top of that when TCO analysis is carried out there is no consideration of the project's benefits, only costs are taken into the account. But the important point for most organizations when choosing a system is to choose one that provides the greatest benefits for the organization, 
Nucleus Research (2007). Even during allocating these costs to different items it is difficult to decide whether, and to what extent certain costs should be allocated to an asset.

According to Microsoft (2006) and Gartner (2007), TCO analysis puts a long-term view into the cost of ICT infrastructure. Costs are considered from acquisition to the disposal of an asset. This means that if an organization intend to cut cost immediately, TCO is not very useful. The other problem here is that allocating these costs correctly depends on accurate forecasting and historical data. Since historical data may not be available for new technologies (as is the case with most ICT technologies) and forecasting is more art than science, this long-term view of costs may yield inaccurate TCO results.

On top of that TCO does not account for risk or the time value money. By not accounting for risk or the time value of money, the overall TCO value does not represent the true cost of ownership of the solution. The true value of a project needs to incorporate two important aspects in financial analysis: risk and time value of money.

\section{How to Reduce TCO}

Gartner Group (2003), Toshiba (2005) and Garrett, David (2004) point out various ways costs can be reduced for a typical ICT infrastructure. Options include reducing costs during computer deployment, using zero administration for Windows (ZAW), automating system administration, storage and operational tasks, training employees, and using best practices. Others include removing unnecessary portions of System, using standard software and hardware, and changing hardware. The amount of saving can range from $14 \%$ to $42 \%$ Gartner (2008).

\section{Methodology Used:-}

Findings presented and discussed in the next part were obtained from IAA. The author made interviews with personnel in the ICT Services and procurement sections as well as reviewed documents relevant to this study. Five (5) staff who were in position to provide data required by the author were consulted. The study aimed at knowing costs for implementing and operating ICT infrastructure at IAA.

\section{Presentation and Discussion of Basic Elements Constituting TCO of Implementing and Operating ICT Infrastructure at IAA}

The Institute of Accountancy Arusha (IAA) is a higher learning institution with approximately 140 employees and more than 2707 students.

The total number of computers at the Institute of Accountancy Arusha is approximately 665. The computers are distributed in staff offices and student laboratories - for use by both of them.

All staff computers and most of students' computers are connected to the local area network and the Internet making easy and possible for them to access resources on the network like; shared printers, templates (for memo, letters and fax). Also electronic mail services by both Microsoft Outlook program and web based electronic mails (e.g. yahoo and Google) are possible. Among other things, staff and students at IAA use the Internet as source of class notes.

The Institute has 14 Server computers, serving as file servers, email servers, print servers, web portals and domain controllers.

There are also 19 printers distributed in various buildings for use by both staff and students. Mainly two types of printers are used at the Institute both of which are of HP type - 9 HP 2100 which cost \$2,500 and 9 HP 4,350 which costs $\$ 5,000$. Other printers are of other types. The total cost of printers amount to $\$ 67,500$.

The approximated cost for a single client computer is $\$ 1,000-1,100$ and for a Server computer is $\$ 6,000$ depending on specifications. Client computers are bought in bulk and therefore there are discount given.

Year after year, specifications (capabilities) of computers like primary and secondary storage and processing speed increases significantly but their costs don't increase much. Assuming each client computer cost $\$ 1,000$ and each Server computer cost $\$ 6,000$, the total amount paid for all client and Server computers is $\$ 748,000$.

Other than costs explained above; the Institute also faces other costs. They are as presented and discussed below; 


\section{Maintenance}

To have ICT infrastructure produce intended results in an efficient way you should maintain it. IAA carries both software and hardware maintenance to ensure that the systems are available and are working as expected.

According to ISO/IEC 14764, in software engineering, software maintenance is the modification of a software product after delivery to correct faults, to improve performance or other attributes, or to adapt the product to a modified environment. But the kind of maintenance done on software here involves correcting minor problems to make software run smoothly and efficiently. This includes uninstalling and reinstalling software, updating and repairing. These maintenances are carried whenever a need arise but these do not cost much the Institute.

The basic aim for hardware maintenance is the same as that for software maintenance. Minor hardware maintenances are done whenever a need arise. For example removing a computer virus from a staff's computer and servicing staff's mouse. However, there are two major maintenances in a year: that which is done annually and that which is done semi annually.

The annual maintenance is done during long break (from mid July to end of September). This involves servicing laboratory equipments (hard disks, computer fans, RAM and computer startup problems), Server rooms, and power equipments. This costs the Institute approximately Tshs. 3 million for labor and equipments.

Semi annual maintenance involves servicing Server equipments and generators. This costs Tshs. 500,000/= and for a year they cost Tshs. 1 million.

\section{Software Licenses}

Software licenses costs the Institute Tshs. 10 million - 15 million per year. Software license comprises the permissions, rights and restrictions imposed on software. Software which requires to pay for licenses which are used at the Institute are Microsoft Windows operating system, Microsoft Office programs, Microsoft Outlook, Microsoft for Intranet share point services and Microsoft terminal services. Initial costs for the software used at the Institute vary from $\$ 0$ to 6,000 . As years pass, costs go down as the Institute moves to open source software.

\section{Human Resource}

The Institute pays a number of people to run its Information Technology infrastructure and systems. These include staff and students.

Currently, there are eleven staff permanently employed and one temporary staff. A total cost for maintaining these employees is Tshs. 85 million per year. Cost for hiring students to work as laboratory assistants is approximately Tshs. 7.2 million per year.

\section{Training}

To have staff work efficiently, training should be provided. Different types of training are provided. The Institute finances training to both users and supporters of its Information Technology systems. Both in house and external training are financed.

Ready qualified computer technicians are employed but short time and sometime long time training is a must as some one can not know each system existing and which will be developed. An example is VSAT training in recent days. Tshs. 12 million is allocated for this exercise per year.

User training is normally done in house. In this case, an expert on particular software from within or outside the Institute will provide training to the Institute staff. Examples of these training are those on MOODLE, accounting programs like QuickBooks and TAS books 2. Tshs. 6 million is allocated for this exercise per year.

Three (3) ICT support staff pursued their first degree studies at various higher learning Institutions in Tanzania. The Institute financed them. Later on, more could be financed even for higher studies other than Bachelor degree level.

\section{Obsolesce and Depreciation}

Obsolesce and depreciation is another factor to consider when making a plan to implement an IT infrastructure in the organization. Obsolescence is one cause of depreciation; it is the degradation in the value and usefulness of a resource based on its age, replacement by newer technology, lack of demand or other factors that may require a partial or total write-off of its currently-stated value. The Institute has 20 Siemens and Legends computers which are 
in good condition but can not be used as they can not meet current software requirements which require big memory and fast processing speed. After five years client computers becomes zero rated. Server computers are considered not useful after 10 years.

\section{Bandwidth}

Bandwidth is another category that cost the Institute a significant amount of money. There was a time the Institute was using VSAT. In 2004 - 2005, when the Institute had a radio link to habari (Arusha node marine), it was paying $\$ 750$ per month with a connection speed of $135 \mathrm{Kbs}$. In $2005-2006$, it was paying \$ 900 per month with a connection of $162 \mathrm{Kbs}$. With a connection speed of $190 \mathrm{Kbs}$ in $2006-2007$, the Institute was paying \$2,000 per month. With VSAT Internet technology in operation, the Institute paid \$ 4,800 per month with a connection speed of $1128 \mathrm{Kbs}$. This means, every year the Institute paid $\$ 57,600$. And to add on top of this, every year a dollar increases its value against a Tanzania shilling. Remember that ICT devices and services are mostly priced in US Dollars.

\section{Power Issues}

Power related issues add considerable burden to the Institute. With more than 665 computers and a number of printers and other devices, there is a significant consumption of power. Also, because of power fluctuation which is the main cause of computer damages the Institute has been forced to buy a big generator which costed a considerable amount of money. AVS (Automatic Voltage Switch) and AVR (Automatic voltage regulator) are bought for each computer laboratory for power protection. The cost for each AVS and AVR is Tshs. 5 million. With 10 computer laboratories operating at the Institute, the total cost for the devices is Tshs. 50 million. In server room, there is a battery backup costing Tshs. 10 million. To add to that, to prevent computers and printers from power fluctuations, each computer and printer is connected to the UPS (uninterrupted power supply). With 665 computers, 19 printers and each UPS costing \$ 150, the Institute paid a total sum of \$ 102,600.

\section{Hardware Installations}

Installations which involve cabling of the devices in a network costed the Institute a sum of Tshs 25 million for each of the five buildings available. Within this amount there are costs for buying data cabinets, switches, cables and RJ 45. In sum, the Institute had to part with Tshs. 125 million to do the installations in the five buildings.

\section{Furniture in Computer Labs}

Each of the 10 computer labs has chairs and tables for computers. The cost for a table on which 2 computers are placed is Tshs. $250,000 /=$. The cost for a single chair is Tshs. $40,000 /=$. With a total number of 225 tables and 450 chairs the Institute used a total of Tshs. 74,250,000/=.

And to prevent theft, each computer room door and window is grilled. Computers' system cases are housed to prevent theft of RAM chips, hard disks etc. There are 450 computer cases and with each case costing Tshs. $70,000 /=$, a total of Tshs. $31,500,000 /=$ was paid.

\section{Similar Studies on Base Elements for Determining ICT TCO}

This study agrees with a number of studies. Studies below point that organizations must consider future costs when investing in ICT infrastructures. For example, in a study by APC (2005) that aimed at determining TCO for data center and network room infrastructure it was found that the TCO of a rack in a data center is approximately $\$ 120,000$ over the data center lifetime. Furthermore, it was found that approximately half of the lifetime per rack TCO of $\$ 120,000$ is capital expense, and half is operating expense. Pearce-Tomenius, Nicholas \& Morgan, Jon (2009) in their paper "TCO Analysis Elements and Arguments", which addressed TCO of digital information archiving solutions, base elements discussed were infrastructure costs and data management and man power costs. Infrastructure costs were power, cooling, network, floor space and fall over facilities. Data management and manpower costs discussed were cost of employees, maintenance costs, obsolesce and migration, duplication, replication \& failover, restoring content (or not), full workflow support and exit costs. Data hint and manpower costs were found to be higher compared to infrastructure costs. In both studies it can be seen that other costs other than initial purchase costs were significant and hence the need to consider them when planning for ICT infrastructures.

This study also agree with that of Colin (2009) in a study titled "Wireless Network Drive Test Tools - Lowering the TCO". The following costs were found in the first year for base elements; Purchasing $80.6 \%$, Training $18.2 \%$, installation and implementation costs $1.2 \%$, Support services costs $0 \%$, Functional change upgrades costs $0 \%$ and Technology upgrades costs $0 \%$. However, after five years of operation the cost elements were found at the following levels: Purchasing 42.9\%, Training 9.7\%, Installation and implementation costs 0.6\%, Support services costs 25.8\%, 
Functional change upgrades costs 5.8\% and Technology upgrades costs $15.2 \%$. This shows that there was decrease in costs for purchasing, training, Installation and implementation while there was an increase in costs for support services, Functional change upgrades and Technology upgrades.

Drury (2001) points that major cost category of ICT TCO are hardware costs, systems and applications, administrative support and finally, the hidden costs. His estimates of cost indicate that starting with hardware costs, systems and applications cost add 0.8 or 1.8 times the cost of hardware, Administration and support increase the costs 4.0 times hardware costs and with the hidden costs, 6.5 times more.

\section{Conclusion:-}

TCO should be calculated by all organizations as is a useful metric for assessing the overall cost of an ICT investment. To properly assess TCO, organizations must look beyond initial acquisition costs to the larger yet more intangible costs, such as those for ongoing administration, the cost of system downtime etc. Organizations can reduce ICT TCO by employing management best practices in acquiring and later use of the technology.

\section{Bibliography:-}

1. ASEAN (2011) ASEAN ICT Master Plan 2015 The ASEAN Secretariat, Jakarta

2. Bankole, F. O., Osei-Bryson, K., \& Brown, I. (2013) The impact of information and communication technology infrastructure and complementary factors on Intra-African trade Information Technology for Development

3. Bollou, F. (2010) Interrogating the impact of ICT infrastructure expansion in francophone West Africa 19932005 A critical theory study using Archival data and non-parametric research methods (Doctoral Thesis) University of Cape Town, Cape Town.

4. Chisnall, David (2006) Making Effective Software TCO Calculations [online] available from <http://www.phptr.com/articles/article.asp?p=458170\&seqNum=2\&rl=1> [13 January 2010]

5. Compugen (2007) Total Cost of Technology (TCT) Assessments [online] available from <http://www.compugen.com/index.asp?ID=tcoassessments> [13 January 2010]

6. Garrett, David (2004) Look before You Leap - How to Evaluate TCO before Buying Equipment [online] available from $<$ http://www.processor.com/editorial/article.asp?article=articles\%2Fp2641\%2F20p41\%2F20p41.asp\&guid=\&s earchtype $=\&$ WordList $=\& b J u m p T o=$ True $>[15$ December 2010]

7. Gartner (2003) A Report and Estimating Tool for K-12 School Districts - Why Total Cost of Ownership (TCO) Matters [online] available from 〈https://k12tco.gartner.com/home/homepagepromo/files/TCO_Overview.pdf> [11 November 2009]

8. Gartner Group (2007) Gartner Applied Methodology Total Cost of Ownership (TCO) tools [online] available from <http://amt.gartner.com/TCO/index.htm> [10 October 2009]

9. GİRAY, G. \& TÜZÜN, E. (2018) A Systematic Mapping Study on the Current Status of Total Cost of Ownership for Information Systems [online] available from https://dergipark.org.tr/en/download/articlefile/465730 [11 March 2019]

10. Investopedia(2019) Direct Cost [online] available from https://www.investopedia.com/terms/d/directcost.asp [11 March 2017]

11. Jeremy, G., Charles K., Christine Zhen-Wei Qiang (2004) Information and Communication Technologies and Broad-Based Development A Partial Review of the Evidence [online] available from http://documents.worldbank.org/curated/en/998881468780319383/pdf/279490PAPER0WBWP0no1012.pdf [11 March 2017]

12. Jorgenson, D. W., \& Vu, K. (2005) Information technology and the world economy. Scandinavan Journal of Economics, 107(4), 631-650.

13. Kauffman (2000) Total cost of ownership white paper [online] available from <http://ids.csom.umn.edu/faculty/kauffman/courses/8420s98/Project/TCO/tco-1.html> [10 October 2009]

14. Kooshki, M. F., \& Ismail, R. (2011) The impact of information and communication technology investment on economic growth in newly industrialized countries in Asia Australian Journal of Basicand Applied Sciences

15. Kuppusamy, M., \& Santhapparaj, S. (2005) Investment in information and communication technologies and its payoff in Malaysia. Perspectives on Global Development and Technology, 4(2), 147-168.

16. Microsoft (2006) Get the Facts: Total Cost of Ownership [online] available from <http://download.microsoft.com/download/a/0/6/a0628eee-0114-4444-9793e52a92dc4cf4/GetTheFacts_ExecSummary_TCO.DOC> [18 December 2009] 
17. Odellion (2007) Total cost of ownership [online] available from <http://www.odellion.com/pages/online\%20community/TCO/financialmodels_tco_definition.htm> [20 December 2009]

18. Osten, Marc (2001) Total cost of ownership - the hidden costs of technology [online] available from <http://www.techsoup.org/learningcenter/techplan/page4761.cfm> [10 January 2010]

19. Shirazi, F., Gholami, R., \& Higon, D. A. (2009). The Impact of Information and Communication Technology (ICT), education and regulation on economic freedom in Islamic Middle Eastern countries Information and Management, 46(9), 426-433.

20. Thompson, H., \& Garbacz, C. (2008) Broadband impacts on state GDP: direct and indirect impacts Paper presented at the International Telecommunications Society 17th Biennial Conference, Canada.

21. Toshiba (2007) TCO Model - a closer look at Personal Computers [online] available from <http://www.toshibaeurope.com/computers/tnt/tco/index.htm> [10 December 2009]

22. Toshiba-europe (2018) IT Strategy - A Closer look at PCs, https://www.toshibaeurope.com/computers/tnt/tco/index.htm [12 March 2019]

23. Wikipedia (2008) Total cost of ownership [online] available from <http://en.wikipedia.org/wiki/Total_cost_of_ownership> [10 December 2009]

24. Wikipedia (2019) Total cost of ownership [online] available from https://en.m.wikipedia.org/wiki/Total_cost_of_ownership [11 March 2017]

25. Worldbank (2011) Africa's ICT Infrastructure - Building on the Mobile Revolution [online] available from https://openknowledge.worldbank.org/bitstream/handle/10986/2325/632510PUB0ICT000ID0184540BOX3615 12B.pdf?sequence=1 [10 March 2017]. 